\title{
Coordination of Converter and Fuel Cell Controllers
}

\author{
Kyung-Won Suh and Anna G. Stefanopoulou
}

\begin{abstract}
Load-following fuel cell systems depend on control of reactant flow and regulation of DC bus voltage during load (current) drawn from them. To this end, we model and analyze the dynamics of a fuel cell system equipped with a compressor and a DC-DC converter. We then employ modelbased control techniques to tune two separate controllers for the compressor and the converter. We demonstrate that the lack of communication and coordination between the two controllers entails a severe tradeoff in achieving the stack and power output objectives. A coordinated controller is finally designed that manages the air and the electron flow control in an optimal way. Our results could be used as a benchmark of achievable fuel cell performance without hybridization.
\end{abstract}

\section{INTRODUCTION}

Portable, stationary and automotive propulsion power applications impose stringent requirements on the transient behavior of proton exchange membrane (PEM) fuel cells (FC). Transient response is a key characteristic feature of backup power system, sometimes more critical than efficiency, due to the importance of accepting uncertain electric loads. Fast transient response is also essential for autonomy in startup and fast power response for automotive fuel cells. For these reasons, every fuel cell power system is expected to produce power on demand, also known as, a load-following fuel cell. Fuel cells, however, are typically known to be slower than any other power sources due to the complex dynamics associated with mass and heat balances inside and outside the stack. To address these limitations, a PEM fuel cell system is typically combined with a battery or capacitor into a hybrid power generation system.

A complete PEM fuel cell power system includes several components apart from the fuel cell stack and battery, such as an air delivery system which supplies oxygen using a compressor or a blower, a hydrogen delivery system using pressurized gas storage or reformer, a thermal and water management system that handles temperature and humidity, DC-DC converters to condition the output voltage and/or current of the stack and finally electric loads [1], [2]. Fig. 1 shows the configuration of a typical fuel cell power system which is constructed with fuel cell, DC-DC converter and battery.

The DC-DC converter transforms unregulated DC power of the FC to regulated DC bus power. Research on the DC-DC converters for fuel cells is focused on soft voltage source which accounts for the cell voltage variation due to the electrochemical characteristic at different operating

This work is funded by NSF 0201332 and the Automotive Research Center (ARC) under U.S. Army contract DAAE07-98-3-0022.

K.-W. Suh and A. G. Stefanopoulou are with the Department of Mechanical Engineering, University of Michigan, Ann Arbor, MI 48109, USA kwsuh, annastef@umich. edu

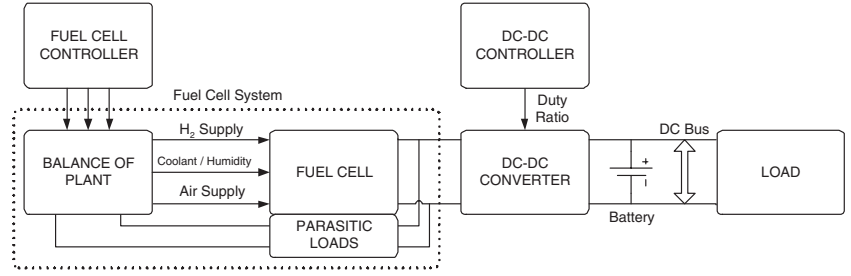

Fig. 1. Block diagram of a typical fuel cell power system

conditions [3]. Sometimes the converter is used to filter the current from the fuel cells to avoid imposing transients that can lead to FC failure or degradation. In both cases, the coupled dynamics of current and voltage in fuel cells and converter affect the system performance. Specifically, limiting the current drawn from the fuel cell enhances fuel cell performance but degrades the voltage regulation performance in DC-DC converter. This direct conflict is typically addressed with hybridization.

The purpose of this paper is to mitigate the two conflicting objectives of a FC power system which is augmented with a DC-DC converter but without a battery. We first develop physics-based model for reactants supply dynamics of the fuel cell stack and the power electronics of DCDC converter. The fuel cell stack and reactant flow models are based on electrochemistry, mass balances for lumped volumes in the stack and peripheral volumes, and rotational dynamics of compressor and motor. In this paper, we introduce another important aspect of the air flow control, namely, the dynamic coupling between the compressor and the fuel cell when the compressor motor is driven by the stack power. The actual converter operates by switching pulse devices, but it is approximated by an average model that captures input-output dynamics within the bandwidth of switching frequency.

In the controller design stage, the fuel cell reactants' supply and DC-DC converter are treated separately. In other words, the controller is first designed for the best performance of each plant in a decentralized fashion. Then, each controller is re-tuned sequentially in favor of the other because there is a direct conflict between performance objectives of the fuel cells and the converter. We then introduce coordination in a combined system controller with optimal gains. The coordinated control accounts for the interactions between the two systems and allows us to construct a controller for the best possible performance. The results of the dynamic model analysis and control study in this paper provides the insight on the fundamental system performance and limitations in handling transient load in a fuel cell power system. 


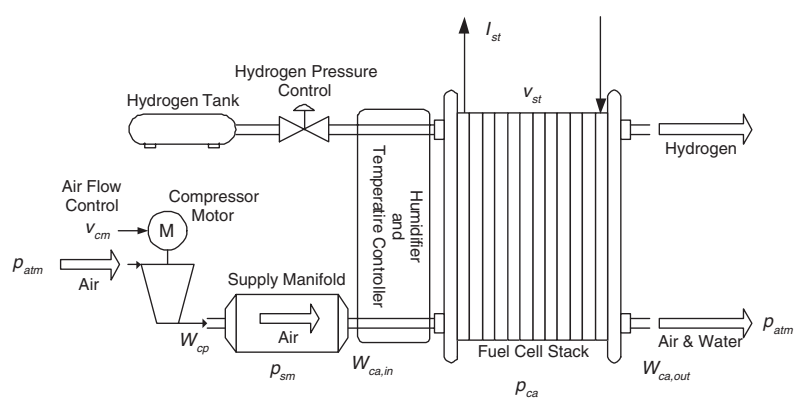

Fig. 2. Fuel cell reactants supply system

\section{FUEL CELL SYSTEM WITH AIR FLOW CONTROL}

We consider a fuel cell stack with active cell area of $A_{f c}=280 \mathrm{~cm}^{2}$ and $n=381$ number of cells with $75 \mathrm{~kW}$ gross power output that is applicable for automotive and residential use. The performance variables for the FC power system are (i) the stack voltage $v_{s t}$ that directly influences the stack power generated $P_{f c}=v_{s t} I_{s t}$ when the load (current) $I_{s t}$ is drawn from the stack, and (ii) the oxygen excess ratio $\lambda_{\mathrm{O}_{2}}$ in the cathode that indirectly ensures adequate oxygen supply to the stack.

Stack voltage is calculated as the product of the number of cells and cell voltage $v_{s t}=n v_{f c}$. The combined effect of thermodynamics, kinetics, and ohmic resistance determines the output voltage of the cell

$$
v_{f c}=E-v_{a c t}-v_{o h m}-v_{c o n c}
$$

where $E$ is the open circuit voltage, $v_{a c t}$ is the activation loss, $v_{o h m}$ is the ohmic loss, and $v_{\text {conc }}$ is the concentration loss. The detailed equation of the FC voltage, also known as, polarization characteristic can be found in [4]. Depending on the load (current) drawn from the fuel cell and the air supply to the fuel cell, the stack voltage varies between $200 \mathrm{~V}$ to $300 \mathrm{~V}$.

The FC voltage is given as static function of current density $i_{f c}=I_{s t} / A_{f c}$ and several other variables such as oxygen and hydrogen partial pressures $p_{\mathrm{O}_{2}}$ and $p_{\mathrm{H}_{2}}$, cathode pressure $p_{c a}$, temperature $T_{s t}$ and humidity $\lambda_{m}$. Although we assume instantaneous electrochemical reaction and negligible electrode double layer capacity, the FC voltage has a rich dynamic behavior due to its dependance on dynamically varying stack variables $\left(i_{f c}, p_{\mathrm{O}_{2}}, p_{c a}, p_{\mathrm{H}_{2}}, T_{s t}, \lambda_{m}\right)$. We assume a compressed hydrogen supply as shown in Fig. 2 that simplifies the control of anode reactant flow. The cooler and humidifier are neglected for this work.

The oxygen is supplied through the air supply and it is typically achieved with a blower or a compressor. When the air is supplied by a compressor, a motor with maximum power of $15 \mathrm{~kW}$ is considered. The maximum compressor air flow is twice the air flow necessary to replenish the oxygen consumed from the stack when the maximum current is drawn $I_{s t, \max }=320 \mathrm{~A}$, which is defined as the current at which the maximum FC power is achieved.

Although the compressor absorbs a significant amount of power and increases the fuel cell parasitic losses, it is preferred to a blower due to the resulting high power density $\left(\mathrm{kW} / \mathrm{m}^{3}\right)$. The tradeoff between satisfying net power requirements and maintaining optimum oxygen excess ratio in the stack during load step changes is first defined in [4]. We show here that this tradeoff is more critical when the compressor motor draws its power directly from the fuel cell instead of an auxiliary power source. The limitations are analyzed in Section II-C after developing a low order fuel cell model in Section II-A and II-B. A proportional integral (PI) controller is developed in Section II-C. For the air flow controller we assume fast changes in the load (current) drawn from the fuel cell. In Section III we investigate how DC-DC converter can be used to filter fast load changes.

\section{A. Dynamic states}

The dynamic behavior of the variables associated with the air flow control, namely, oxygen pressure $p_{\mathrm{O}_{2}}$, total cathode pressure $p_{c a}$, and oxygen excess ratio in the cathode $\lambda_{O_{2}}$ can be found in [4], [5]. The flow dynamics of the oxygen and hydrogen reactants are governed by pressure dynamics through flow channels, manifolds, orifices. Several simplifications and modifications have been employed to allow us to concentrate on the fast dynamics associated with the integration of a fuel cell with a converter.

We present the model dynamic states first and then in section II-B we describe the nonlinear relationships that connect the inputs with the states and the outputs.

The mass continuity of the oxygen and nitrogen inside the cathode volume and ideal gas law yield

$$
\begin{aligned}
& \frac{d p_{\mathrm{O}_{2}}}{d t}=\frac{\bar{R} T_{s t}}{M_{\mathrm{O}_{2}} V_{c a}}\left(W_{\mathrm{O}_{2}, \text { in }}-W_{\mathrm{O}_{2}, \text { out }}-W_{\mathrm{O}_{2}, \text { rct }}\right), \\
& \frac{d p_{N_{2}}}{d t}=\frac{\bar{R} T_{s t}}{M_{N_{2}} V_{c a}}\left(W_{N_{2}, \text { in }}-W_{N_{2}, \text { out }}\right)
\end{aligned}
$$

where $V_{c a}$ is the lumped volume of cathode, $\bar{R}$ is the universal gas constant, and $M_{\mathrm{O}_{2}}$ and $M_{N_{2}}$ are the molar mass of oxygen and nitrogen, respectively.

The compressor motor state is associated with the rotational dynamics of the motor through thermodynamic equations. A lumped rotational inertia is used to describe the compressor with the compressor rotational speed $\omega_{c p}$

$$
\frac{d \omega_{c p}}{d t}=\frac{1}{J_{c p}}\left(\tau_{c m}-\tau_{c p}\right)
$$

where $\tau_{c m}$ is the compressor motor torque and $\tau_{c p}$ is the load torque of the compressor.

The rate of change of air pressure in the supply manifold that connects the compressor with the fuel cell (shown in Fig. 2) depends on the compressor flow into the supply manifold $W_{c p}$, the flow out of the supply manifold into the cathode $W_{c a, i n}$ and the compressor flow temperature $T_{c p}$

$$
\frac{d p_{s m}}{d t}=\frac{\bar{R} T_{c p}}{M_{a, a t m} V_{s m}}\left(W_{c p}-W_{c a, i n}\right)
$$

where $V_{s m}$ is the supply manifold volume and $M_{a, a t m}$ is the molar mass of atmospheric air. 


\section{B. Nonlinear static functions}

The inlet mass flow rate of oxygen $W_{O_{2}, \text { in }}$ and nitrogen $W_{N_{2}}$,in can be calculated from the inlet cathode flow $W_{c a, i n}$ as follows

$W_{\mathrm{O}_{2}, i n}=\frac{x_{\mathrm{O}_{2}, a t m}}{1+w_{a t m}} W_{c a, i n}, W_{\mathrm{N}_{2}, i n}=\frac{1-x_{\mathrm{O}_{2}, a t m}}{1+w_{a t m}} W_{c a, i n}$

where $x_{\mathrm{O}_{2}, \text { atm }}$ is the oxygen mass fraction of the inlet air associated with the oxygen molar ratio $y_{\mathrm{O}_{2}}, \mathrm{~atm}=0.21$ and $w_{\text {atm }}$ is the humidity ratio of inlet air.

The supply manifold model describes the mass flow rate from the compressor to the outlet mass flow. A linear flowpressure condition $W_{c a, i n}=k_{c a, i n}\left(p_{s m}-p_{c a}\right)$ is assumed due to the small pressure difference between the supply $\operatorname{manifold}\left(p_{s m}\right)$ and the cathode pressure $p_{c a}$ which is the sum of oxygen, nitrogen and vapor partial pressures $p_{c a}=$ $p_{\mathrm{O}_{2}}+p_{N_{2}}+p_{\text {sat }}$ with the vapor saturation pressure $p_{\text {sat }}=$ $p_{\text {sat }}\left(T_{s t}\right)$. The total flow rate at the cathode exit $W_{\text {ca,out }}$ is calculated by the nozzle flow equation [6] because the pressure difference between the cathode and the ambient pressure is large in pressurized stacks.

The rate of oxygen consumption $W_{\mathrm{O}_{2}, r c t}=M_{\mathrm{O}_{2}} \frac{n I_{s t}}{4 F}$ in (2) depends on the stack current $I_{s t}$ and the Faraday number $F$. The oxygen excess ratio

$$
\lambda_{O_{2}}=\frac{W_{O_{2}, i n}}{W_{O_{2}, r c t}}
$$

is typically regulated at $\lambda_{\mathrm{O}_{2}}^{\text {ref }}=2$ to reduce the formation of stagnant vapor and nitrogen films in the electrochemical area. Values of $\lambda_{\mathrm{O}_{2}}$ lower than 1 indicate oxygen starvation and has serious consequences in the stack life.

The compressor motor torque $\tau_{c m}=P_{c m} / \omega_{c p}$ depends on the power $P_{c m}=v_{c m}\left(v_{c m}-k_{v} \omega_{c p}\right) / R_{c m}$ provided by the compressor motor, which is calculated using the compressor motor voltage input $v_{\mathrm{cm}}$ and its rotational speed $\omega_{c p}$. In this paper, the compressor power is supplied directly from the fuel cell (Fig. 1).

\section{Control of air supply control}

The FC compressor is controlled to supply the air flow to the cathode that is necessary for the reaction associated with the current drawn $I_{s t}$ from the fuel cell [7]. For several reasons [5], [8], air supplied to the cathode should exceed the air necessary for reaction. The oxygen excess ratio $\lambda_{O_{2}}$ is a convenient lumped variable, which if regulated to a desired value $\left(\lambda_{O_{2}}^{r e f}=2\right)$ it ensures adequate supply of oxygen in the cathode.

We consider here the case where the compressor is driven from the fuel cell. The input current, $I_{i n}$, which is the current from the FC to the DC-DC converter, can be calculated from fuel cell stack current $I_{s t}$, and the current load of compressor $I_{c m}$ in $I_{s t}=I_{i n}+I_{c m}$. Here it is considered that the compressor motor contributes to the largest percent of parasitic losses. The compressor current $I_{c m}$, is calculated from the power drawn by the compressor $P_{c m}$ and the stack voltage $v_{s t}: I_{c m}=P_{c m} / v_{s t}$. Thus
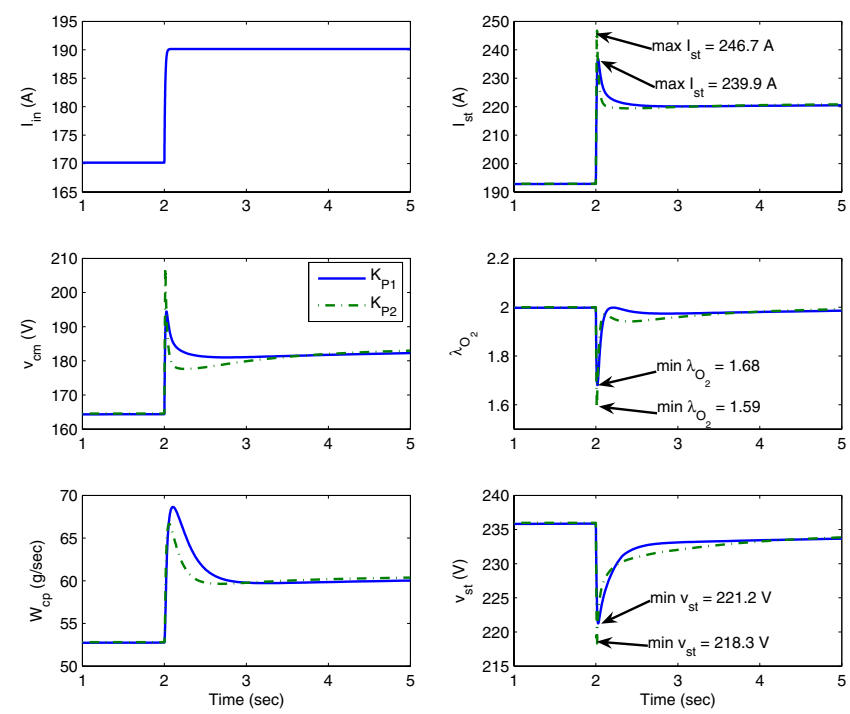

Fig. 3. Fuel cell control simulation

compressor current is implemented so that $P_{c m}$ is simply drawn from the stack through a fast filter that emulates the compressor motor control unit.

The control objective of regulating the performance variable $\lambda_{\mathrm{O}_{2}}$ can be achieved by a combination of feedback and feedforward algorithms that automatically define the compressor motor voltage input $v_{c m}$. Since the oxygen excess ratio $\lambda_{\mathrm{O}_{2}}$ is not directly measured, we control $\lambda_{\mathrm{O}_{2}}$ indirectly measuring the compressor flow $W_{c p}$ and the demanded load $I_{s t}$. Specifically, feedforward control to air compressor voltage $v_{c m}^{f f}$ can be applied based on the stack current $I_{s t}, v_{c m}^{f f}=f\left(I_{s t}\right)$. The function $f\left(I_{s t}\right)$ is determined by the balance of oxygen mass consumed for the stack current and the compressor map from $v_{c m}$ to $W_{c p}$. The feedforward control can accurately regulate $\lambda_{\mathrm{O}_{2}}$ to its desired value at steady state if all the model parameters are known. To reduce potential errors associated with modeling errors or device aging, a feedback controller $v_{c m}^{f b}$ can be combined with the feedforward controller based on the compressor flow measurement $W_{c p}$. The feedback controller ensures that the compressor flow reaches fast a desired value $W_{c p}^{r e f}$ that is calculated based on $I_{s t}$ [7]. A PI controller can be applied to the difference of $W_{c p}$ and $W_{c p}^{\text {ref }}$.

Fig. 3 shows the closed-loop performance for two different controller gains $K_{p}$. During a step input of net current $I_{i n}$ the oxygen excess ratio initially drops because the additional air flow that can compensate the amount of increased current has not yet reached the cathode. The oxygen excess ratio $\lambda_{\mathrm{O}_{2}}$ recovers quickly due to the feedforward control and settles to the desired steady-state value with no error due to the PI controller. Higher controller gain shown in dashed line improves the $W_{c p}$ tracking performance by employing larger control input signal $v_{\mathrm{cm}}$. Despite the improvement in $W_{c p}$, the $\lambda_{O_{2}}$ regulation degrades. The reason for this degradation is discussed below. First, the current 
drawn from the fuel cell by the compressor increased in the case of high gain PI controller. Second, the high gain controller decreases the $W_{c p}$ overshoot which delays the delivery of the necessary air flow to the cathode (further downstream the compressor).

Thus, the difficulty and control limitations are more pronounced in the case where the compressor is powered directly by the fuel cell and not an auxiliary power unit. In fact the limitation in controlling oxygen starvation arises from the compressor and fuel cell electric coupling and not from the manifold filing dynamics as frequently quoted in literature [9], [7], [10], [11]. Indeed, when the compressor power is drawn directly from the fuel cell, there is a direct conflict between regulating the compressor air mass flow and regulating the oxygen excess ratio. Fast air flow control requires large compressor power that increases the current drawn from the stack. This direct coupling between the actuator signal $v_{c m}$ and the performance variable $\lambda_{\mathrm{O}_{2}}$ especially at high frequencies exacerbates the difficulties in controlling the air flow to the fuel cell during step increase in load.

\section{DC-DC CONVERTER}

\section{A. DC-DC converter model}

The DC-DC converter transforms the DC fuel cell stack power to output voltage-current requirements of the external power devices that connect to a FC system. Here we consider a boost converter (shown in Fig. 4) that can be used in PEM fuel cell applications. The input voltage $v_{i n}$ and input current $I_{i n}$ of the converter are the FC output voltage and the net FC current. The output voltage $v_{\text {out }}$ and current $I_{\text {out }}$ depend on the duty ratio $d_{1}$ of the solid state switch in the circuit. The inductance of input inductor $L_{i n}$, the capacitance of output capacitor $C_{\text {out }}$ and the resistance of the load $R_{\text {load }}$ are shown in Fig. 4.

In this study, the boost converter is selected for $50 \mathrm{~kW}$ power and based on $400 \mathrm{~V}$ output voltage with nominal input voltage is $250 \mathrm{~V}$ and thus nominal input current is 200 A. For the subsequent dynamic analysis, the values of inductor and capacitor are selected to be as $L_{i n}=1 \mathrm{mH}$ and $C_{\text {out }}=1200 \mu \mathrm{F}$.

An average nonlinear dynamic model can be used to approximate the boost converter switching dynamics [12]

$$
\begin{gathered}
L_{\text {in }} \frac{d I_{\text {in }}}{d t}=v_{\text {in }}-\left(1-d_{1}\right) v_{\text {out }}, \\
C_{\text {out }} \frac{d v_{\text {out }}}{d t}=\left(1-d_{1}\right) I_{\text {in }}-\frac{v_{\text {out }}}{R_{\text {load }}} .
\end{gathered}
$$

The inputs to the converter, based on realistic FC operation, are the duty ratio $d_{1}$, the input voltage $v_{i n}$, and the output current, $I_{\text {out }}=v_{\text {out }} / R_{\text {load }}$. Linearization and Laplace transformation from these inputs to the output voltage $v_{\text {out }}$ provide the following transfer functions [13]

$$
v_{\text {out }}(s)=G_{d}(s) d_{1}(s)+G_{v}(s) v_{\text {in }}(s)-Z_{\text {out }}(s) I_{\text {out }} \text {. }
$$

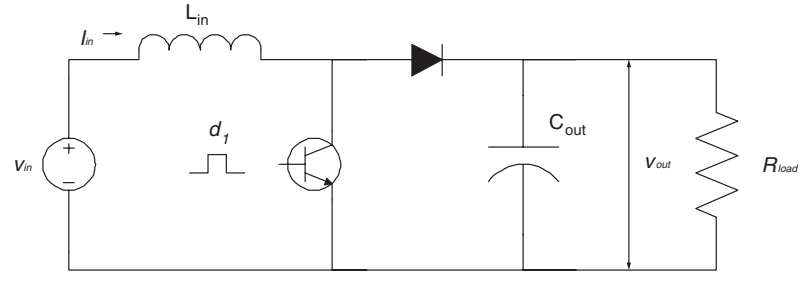

Fig. 4. DC-DC boost converter

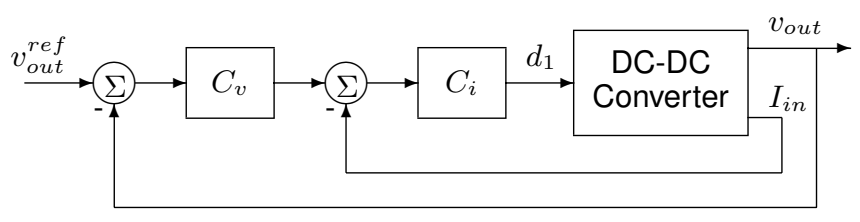

Fig. 5. Sequential loop control

The transfer function $Z_{\text {out }}$ is called converter impedance and represents the effect of small load (current) changes to $v_{\text {out }}$. Due to a zero at the origin of $Z_{\text {out }}$ the steady-sate output voltage is not affected by a step change in load. This capability to reject load disturbances (variation in $I_{\text {out }}$ ) and regulate the output voltage $\left(v_{\text {out }}\right)$ is desirable. However, the transient response during varying load might be worst due to the same reason.

Low damping causes undesirable output oscillations that can be reduced with judicious control design as discussed below. The open loop converter has fast dynamics with natural frequency $\omega_{n}=\left(1-d_{1, n}\right) / \sqrt{L_{i n} C_{o u t}}$ approximately at $1000 \mathrm{rad} / \mathrm{sec}$. The fast converter dynamics cause abrupt changes in $I_{i n}$ and act as a disturbance to the fuel cell. Therefore the converter control design has to reduce this high frequency disturbance to the fuel cell by providing damping, or in other words, filtering the current $I_{i n}$ drawn from the FC.

\section{B. DC-DC converter control}

The converter control objective is to maintain constant bus voltage despite variations in the load and the input (fuel cell) voltage. In fuel cell application the converter operates in large range of power. We thus consider disturbances in $1 / R_{\text {load }}$ that can capture the large load variation better than the output current $I_{\text {out }}$ formulation in (9). We employ linear control techniques similar to [13] and formulate the bus voltage regulation problem using the control structure in [14]. A two-degrees of freedom (2DOF) controller shown in Fig. 5 and presented in [12] is formulated.

In this control scheme, the outer loop controller $C_{v}$ is composed of a PI controller for zero steady-state error. Then the output from $C_{v}$ can be the virtual reference of $I_{i n}$, which becomes the current drawn from the fuel cell when the converter connects to the fuel cell. Nonlinear logic such as slew rate limiter, saturation or any kind of filter can be added to shape the current from the fuel cell stack [3]. Adding a proportional feedback $C_{i}$ around the $I_{i n}$ measurement is equivalent to derivative controller 

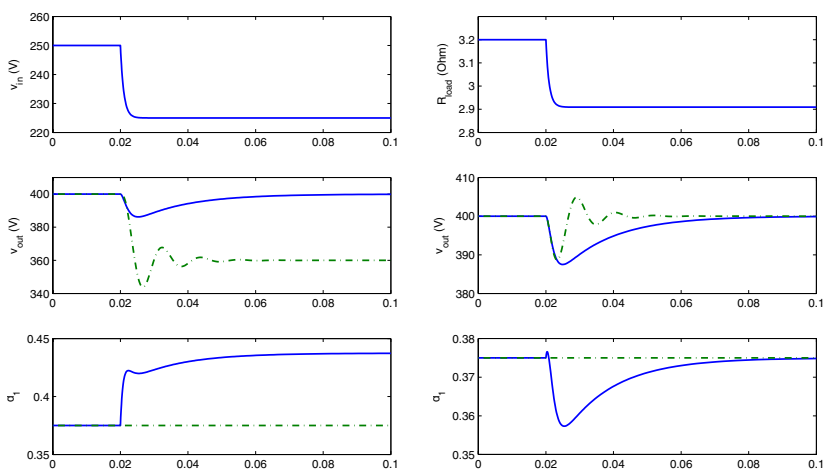

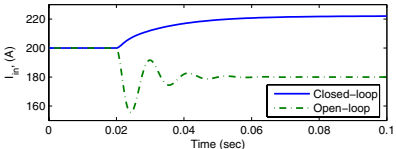

(a) input voltage change

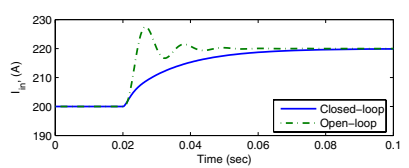

(b) load resistance change
Fig. 6. Simulation results of the DC-DC converter

which is needed to dampen the typically undamped DC-DC converter dynamics as shown in section III-A. Although $C_{i}$ is designed as proportional controller, it acts as a derivative control for $v_{\text {out }}$, because $I_{i n}$ is related to the derivative of $v_{\text {out }}$ as shown in (8).

The controller can be written as

$$
d_{1}(s)=-K_{D v} I_{\text {in }}(s)-K_{P v} v_{\text {out }}(s)-\frac{K_{I v}}{s} v_{\text {out }}(s)
$$

and formulated as state feedback when an integrator is added to the states. The optimal state feedback gains $K_{D v}$, $K_{P v}$ and $K_{I v}$ can be selected from a linear quadratic regulator design [14]. With known gains two equivalent controllers, $C_{v}$ and $C_{i}$, are separated $C_{v}(s)=\frac{K_{P v}}{K_{D v}}+\frac{K_{I v}}{K_{D v} s}$ and $C_{i}(s)=K_{D v}$ to allow a nonlinear current limiter to be inserted for the virtual reference command input to $I_{i n}$.

Fig. 6 shows simulations results of the boost converter with a two-degrees of freedom controller (solid line) and the open-loop performance (dashed line). First a step decrease of input voltage from $250 \mathrm{~V}$ to $225 \mathrm{~V}$ is applied to emulate fuel cell voltage which corresponds to $70 \mathrm{mV}$ average cell voltage drop. During this change, shown in (a), the duty ratio $d_{1}$ increases and draws more current from the input source. The performance variable $v_{\text {out }}$ recovers within 0.1 second. The controller can be tuned to handle the input voltage change faster at the expense of faster transient in current drawn from the fuel cell $I_{i n}$. The graphs in column (b) show the closed-loop response during a load change. The load change corresponds to increase in power from $50 \mathrm{~kW}$ to $55 \mathrm{~kW}$. In this situation, steady-state voltage regulation is not a problem because the DC gain of the impedance transfer function $Z_{\text {out }}$ is zero as discussed in Section III-A. Nevertheless, the controller we design reduces $d_{1}$ for a short time. This decrease helps filter the sharp and oscillatory current in $I_{i n}$ that would have occurred otherwise (shown in dashed line). Here it can be observed that the closed-loop $I_{i n}$ increases and settles to the next steady state level in

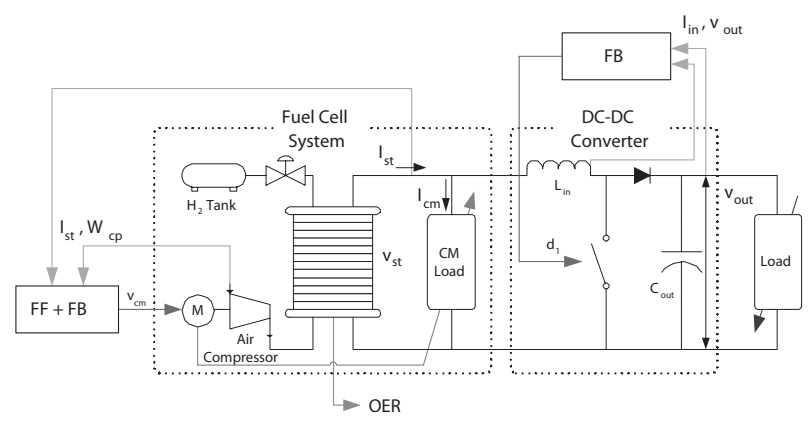

(a) Decentralized control scheme

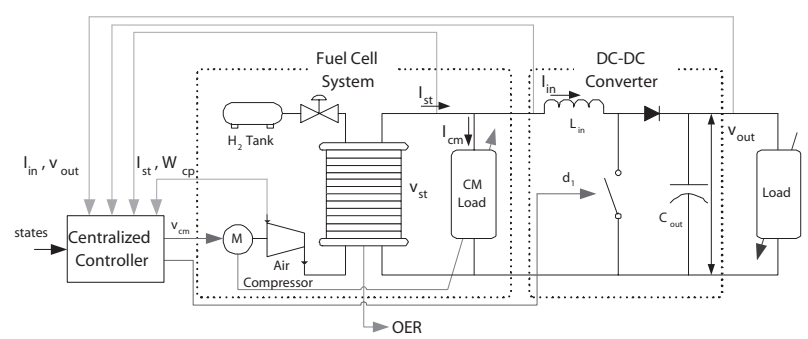

(b) Coordinated control scheme

Fig. 7. Control schemes for fuel cell power system

both input voltage change and output power change. This behavior clarifies the causality between the fuel cell and converter dynamics, where the fuel cell becomes a current source in the output voltage regulation problem.

\section{Connecting the COnVerter With the FC}

The fuel cell, with the controlled compressor, is connected with the controlled converter to form an autonomous power supply. In an industrial application, the fuel cell with its compressor and compressor controller is viewed as one component and the converter with its controller as another as shown in Figure 7(a). Typically, these two components are provided by different manufacturers based on some initial specifications. The two decentralized controllers are calibrated and small corrections are performed after the two components are connected in a sequential fashion to minimize interactions between the two components.

A multivariable controller takes into account the component interaction and results in a centralized controller as shown in Fig. 7(b). The centralized controller, indeed, achieves better performance than the decentralized even after several iterations. Decentralized control is typically successful if there is minimal coupling between the two system. In our case, the performance variables $\lambda_{\mathrm{O}_{2}}$ and $v_{\text {out }}$ are conflicting each other and result in a challenging calibration problem. When the converter controller acts fast to regulate $v_{\text {out }}$, there is large excursion in $\lambda_{\mathrm{O}_{2}}$ due to the sudden input current $I_{i n}$. Detuning of the converter controller is necessary to avoid this fast interaction with the fuel cell. The solid line (DEC2) in Fig. 8 shows the simulation results after the detuning of the DC/DC controller shown initailly in Fig. 6 (DEC1). Now the duty ratio initially decreases even if the the load increases, filtering the FC current and avoiding the 
large $\lambda_{\mathrm{O}_{2}}$ excursion. For these converter gains, the output voltage recovers slowly, demonstrating the severe tradeoff associated with the decentralized architecture controller.

A centralized, multivariable model-based controller is designed to define the optimal signals within the conflict. The optimal control is derived based on the minimization of a cost function that explicitly depends on the performance variable $\lambda_{\mathrm{O}_{2}}$ and $v_{\text {out }}$. The actuator cost also can be added to the cost function to prevent excessive actuator inputs, which is especially useful for the air compressor controller.

The linear simulations of the coordinated controllers with two different cost functions are shown in Fig. 8. A step resistance change input is applied intending to increase output power from $40 \mathrm{~kW}$ to $50 \mathrm{~kW}$. The centralized controller CEN1 in dashed line is designed to match the $v_{\text {out }}$ recovery of the detuned, decentralized controller DEC2, but performs considerably better than the decentralized controller in regulating $\lambda_{\mathrm{O}_{2}}$. The relatively slow recovery of $\lambda_{\mathrm{O}_{2}}$ from all controllers is due to low $v_{\mathrm{cm}}$ controller gain which is already discussed in the FC controller design. The solid line shows that the coordinated controller has the capability to improve both performance outputs at the same time using the optimal design. The output voltage $v_{\text {out }}$ recovers three times faster than the decentralized case without significant degradation of $\lambda_{\mathrm{O}_{2}}$. The control strategy can be observed with the response in the solid line. The duty ratio initially drops to protect the FC while waiting for the air supply to increase. When the compressor ramps up then $d_{1}$ increases rapidly to recover the output voltage $v_{\text {out }}$. These benefits on both performances occur mostly from the communication and coordination in the system.

\section{CONCLUSION}

Modeling and analysis of a load following FC combining a fuel cell system and a DC-DC converter is shown in this paper. A low-order FC system model has been developed using physical principles and stack polarization. The inertial dynamics of the compressor, manifold filling dynamics and partial pressures are captured. An average continuous in time modeling approach that approximates the converter switching dynamics is applied. The direct conflict between the air supply in FC and the voltage regulation in the converter is elucidated.

Then a model-based controller is designed to regulate both the FC oxygen excess ratio and the bus voltage using decentralized and coordinated control architectures. A severe limitation arises when no hybridization dictates that the air supply compressor should be powered directly from the FC. We show that coordination between the compressor and the converter controllers can alleviate the tradeoff between the two performances. This study can be extended to the design and optimization of FC hybrid power system.

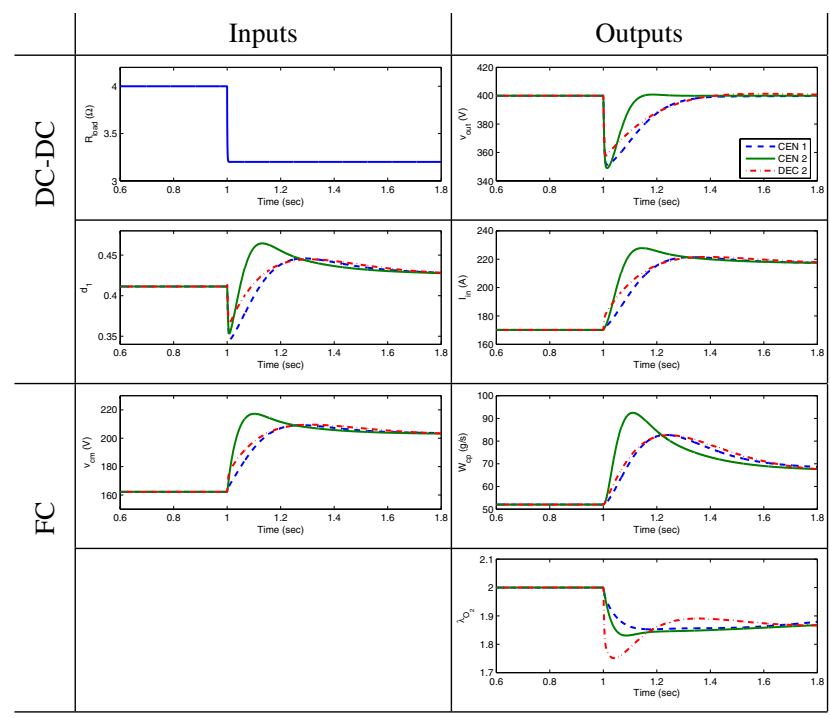

Fig. 8. Simulation results of fuel cell power system: centralized control

\section{REFERENCES}

[1] K. Rajashekara, "Propulsion system strategies for fuel cell vehicles," SAE paper 2000-01-0369, 2000.

[2] W.-C. Yang, B. Bates, N. Fletcher, and R. Pow, "Control challenges and methodologies in fuel cell vehicle development," SAE paper 98C054, 1998.

[3] U.S. Department of Energy, Office of Fossil Energy, and National Energy Technology Laboratory, Fuel Cell Handbook, 7th ed. Morgantown, WV: EG\&G Technical Services, Inc., 2004.

[4] J. T. Pukrushpan, H. Peng, and A. G. Stefanopoulou, "Controloriented modeling and analysis for automotive fuel cell systems," ASME J. Dyn. Syst., Meas., Control, vol. 126, no. 1, pp. 14-25, 2004.

[5] J. T. Pukrushpan, A. G. Stefanopoulou, and H. Peng, Control of Fuel Cell Power Systems: Principles, Modeling, Anylysis and Feedback Design, ser. Advances in Industrial Control. London: SpringerVerlag Telos, 2004

[6] P. Thomas, Simulation of Industrial Processes for Control Engineer. London: Butterworth-Heinemann, 1999.

[7] J. T. Pukrushpan, A. G. Stefanopoulou, and H. Peng, "Control of fuel cell breathing," IEEE Control Syst. Mag., vol. 24, no. 2, pp. 30-46, 2004

[8] G. Boehm, D. P. Wilkinson, S. Khight, R. Schamm, and N. J. Fletcher, "Method and appratus for operating a fuel cell," U.S. Patent 6461751 , Oct. 8, 2002.

[9] J. M. Cunningham, M. A. Hoffman, R. M. Moore, and D. J. Fredman, "Requirements for a flexible and realistic air supply model for incorporation into a fuel cell vehicle system simulation," SAE paper 1999-01-2912, 1999.

[10] P. Rodatz, G. Paganelli, and L. Guzzella, "Optimizing air supply control of a pem fuel cell system," in Proc. Amer. Control Conf., vol. 3, Denver, CO, June 2003, pp. 2043-2048.

[11] J. Sun and I. Kolmanovsky, "Load governor for fuel cell oxygen starvation protection: A robust nonlinear reference governor approach," in Proc. Amer. Control Conf., vol. 1, Boston, MA, June 2004, pp. 828-833.

[12] P. T. Krein, Elements of Power Electronics. New York and Oxford: Oxford University Press, 1998.

[13] R. W. Erickson and D. Maksimovic, Fundamentals of Power Electronics, 2nd ed. Norwell, MA: Kluwer Academic Publishers, 2001.

[14] C. Gezgin, B. S. Heck, and R. M. Bass, "Control structure optimization of a boost converter: An lqr approach," in Proc. IEEE PESC'97, vol. 2, St. Louis, MO, June 1997, pp. 901-907. 